\title{
Narrative Intelligence
}

\section{Michael Mateas}

\author{
Computer Science Department \\ Carnegie Mellon University \\ 5000 Forbes Avenue \\ Pittsburgh, PA 15213 \\ michaelm@cs.cmu.edu
}

\section{Phoebe Sengers}

\author{
Media Arts Research Studies \\ Institut fuer Medienkommunikation \\ GMD \\ Schloss Birlinghoven \\ D-53754 Sankt Augustin Germany \\ phoebe@viswiz.gmd.de
}

\section{Introduction}

People are narrative animals. As children, our caretakers immerse us in stories: fairy tales, made-up stories, favorite stories, "Read me a story!" Even when barely verbal, we begin to tell our own proto-stories. "Phoebe! Pizza! Phoebe! Pizza!" was the excited story of a 2-year-old friend Addie when one of us happened to arrive simultaneously with the pizza delivery man. This story means, approximately, "Can you believe it? Phoebe and pizza came into the house at the same time!" As children, narrative frameworks become an important part of the way we learn to approach the world (Nelson 1989).

As adults, we continue to surround ourselves with stories, furnishing our worlds not just with data but with meaning. We say to one another, "Have you heard? Frank and Barb had a fight. She's sick of him letting the dog on the bed. I always told him he'd get in trouble with his permissive ways with that beast." By telling stories we make sense of the world. We order its events and find meaning in them by assimilating them to more-or-less familiar narratives. It is this human ability to organize experience into narrative form that David Blair and Tom Meyer call "Narrative Intelligence" (Blair and Meyer 1997) and around which AI research into narrative coalesces.

\section{A Brief History of Narrative Intelligence}

Given the primary importance of narrative in human experience, it is no surprise that story and narrative have long been of interest to AI researchers. In the 1970's and early 80 's, there was a substantial amount of interest in story understanding and generation in particular. Work in this area was particularly strong in Roger Schank's research group at Yale. Schank and his group explored the issue of what kind of knowledge structures and process a human being must have to understand the meaning of natural language. Since the meaning of a sentence is not determinable in isolation, but requires relating the sentence

Copyright ( $)$ 1998, American Association for Artificial Intelligence (www.aaai.org). All rights reserved. to sentences around it, to prior experience, and to some larger context, the group's work quickly became focused on understanding narratives. In a series of programs, they developed a theory of the knowledge structures necessary to understand textual narratives. The story-understanding system SAM (Cullingford 1981) used scripts to capture the notion of a stereotyped situations or contexts. The scripts captured the typical causal connections holding in a stereotyped situation. The story-understanding system PAM (Wilensky 1981) and the story-generation system TAIL-SPIN (Meehan 1977) both incorporated a notion of the goals held by characters in a narrative and the various means they have to accomplish these goals. Other work in this group included a model of ideologically-biased understanding (Carbonell 1979), the use of themes to capture aspects of stories more abstract than can be captured just with scripts, plans and goals (Dyer 1983), and a model of narrative memory and reminding (Kolodner 1984).

Work in this area generated an impressive range of systems, particularly given the comparatively primitive hardware technology to which these early researchers were limited. A pleasant discovery for later researchers in rereading these early reports is a level of charm and wit in system design often unfortunately lacking in contemporary research. Nevertheless, these early narrative systems fell out of favor, suffering from the same fate that befell many 70 's AI systems. They were intensely knowledge-based, which meant that they functioned only in very limited domains and could be made more general only by an intensive and probably eventually infeasible knowledge engineering process.

But, perhaps more importantly, as funding for AI dried up during the AI Winter, AI research became more focused on constrained problems with clear measurable results and immediate practical utility. Researchers tried to make AI more like engineering than like a craft or an art. This required focusing on problems with discrete measurable outcomes in which it is possible to say with certainty that a program achieves or does not achieve the given objective. Yet such a research agenda rules out the ability to work on complex phenomena such as the human use of narratives precisely because the complexity of such a phenomenon rules out the possibility for complete, decisively testable models. Schank makes this clear in his description of the 
research agenda at Yale (Schank and Reisbeck 1981, page 4):

Thus, for us, theory creation is a process of thought, followed by programming, then by additional thought, with each serving the other. Thus AI really operated under a novel view of science. Normal scientific method holds that first a theory is postulated, and then tested and found to be right or wrong. But in AI our theories are never that complete, because the processes we are theorizing about are so complex. Thus our tests are never completely decisive. We build programs that show us what to concentrate on in building the next program.

Except for occasional exceptions continuing in the Yale tradition, such as Mueller's model of daydreaming (Mueller 1990) and Turner's model of storytelling (Turner 1992), sustained work on narrative disappeared in AI.

\section{Birth of NI}

While AI research became refocused, narrative became no less important. Narrative influences simply became felt in other areas of computer science. In these other areas, narrative became an influence as part of a general move towards an interdisciplinary engagement with the humanities. For example, in human-computer interface design, the research focus moved from the hardware interface, through programming language as interface and interactive terminal as interface, to a view of the interface as a computer/human dialog (GUI's are based on this model) and a growing concern with the entire use context (including the social context) as the "interface" (Grudin 1989). This shift in the design focus has been accompanied by a shift in system design methodologies, particularly the adoption of qualitative techniques from the social sciences (e.g. ethnography), and the use of iterative design cycles and rapid prototyping. These new methodologies focus on understanding the use context and managing the inherent incompleteness of any description of the use context or the system requirements (Loewgren 1995). As system designers began coping with the rich complexities of designing both for and within a cultural context, they began tapping the long craft tradition of other design fields (e.g. architecture, graphic design, industrial design, etc.) which have been successfully designing artifacts within rich cultural settings for hundreds, if not thousands of years (Winograd 1996). As the field of human-computer interaction became more interdisciplinary (e.g. borrowing anthropological and qualitative sociological techniques), it was just a matter of time before the concept of narrative was examined for interface design principles (Laurel 1991).

Other fields of CS also began tapping humanistic perspectives in general and narrative concepts in particular. For example, in hypertext research, narrative ideas were incorporated, both in the broad sense of narrative as cooperative social construction (Barrett 1989) and in the narrower sense of a narrative as a story written by an author (Bolter and Joyce 1987). Within AI itself, narrative and dramatic concepts reappeared in the form of interactive fiction (Bates 1992, Murray 1998).

Thus, during the same time period in which AI research abandoned studying complex, culturally grounded phenomena such as meaning in favor of narrowly defined problems with decisive, measurable results, other fields of CS moved in the opposite direction, borrowing and adapting modes of knowledge production from the humanities, design and the arts in order to tackle the complexities of designing computational artifacts for and within cultural contexts. And within this general move towards a humanistic/technical fusion, narrative provides a particularly rich set of ideas for informing such work. It is our contention that this engagement with narrative in other fields of CS has opened up a new opportunity for employing narrative in AI.

Specifically, this work (re)establishes the following conditions within the CS culture:

1. Research methodologies which address rich, complex research questions by employing iterative cycles (e.g. the cycle described in the Schank quote above, where one builds to know what to think and thinks to know what to build) have been revalidated.

2. Interdisciplinary technical work drawing heavily on the humanities, design and the arts has proven useful.

3. Narrative has been recognized as a particularly rich constellation of ideas for informing system design.

The time is ripe for AI to reengage narrative, to explore all the ways in which narrative intersects with intelligence of both the artificial and human varieties. Among the first groups to begin this new exploration was a loose-knit circle of interdisciplinary researchers led by Michael Travers and Marc Davis at the MIT Media Lab. They termed this area of work "Narrative Intelligence" (NI). Researchers in the NI group pulled in notions of narrative from other disciplines into a new, creative foment.

\section{Streams of Influence}

One of the central aspects of NI work is its inherent interdisciplinarity. If narrative is indeed, as many argue, a fundamental organizing principle of human experience, then it is unsurprising that many different fields have an interest in narrative. Work in NI has drawn on conceptions of narrative from many of these sources, including the following.

\section{Art}

In art, narrative is understood as one, rather powerful, form of representation. Much of contemporary art practice involves self-consciously questioning representational modes, exploring the boundaries, breaking the representation, questioning whose power is being preserved by a representational mode, and hybridizing modes in order to create new ones. Thus, when engaging in 
narratively-based work, artists rarely tell straightforward narratives employing the standard narrative tropes available within their culture, but rather ironize, layer, and otherwise subvert the standard tropes from a position of extreme cultural self-consciousness. For those studying NI, artistic practice is a useful methodological resource as a way to expose and explore the often unarticulated cultural machinery supporting narrative representation (for an example, see Domike 1999, Mateas 1999).

\section{Psychology}

In psychology, narrative is thought of as a way in which humans make sense of the world. This notion is particularly advanced in Jerome Bruner's work on narrative psychology (Bruner 1990, Bruner 1991). Bruner argues that narrative is fundamental to human understanding of intentional behavior, i.e. that humans make sense of intentional action by assimilating it into narrative structures. This argument is used as a basis for making systems from interfaces to intelligent agents more understandable, by communicating in ways that are easy to assimilate to narrative (Don 1990, Sengers 1999).

\section{Cultural studies}

In cultural studies, narrative is studied as a way in which a culture structures and propagates knowledge. Because humans quickly internalize narrative, it is an important form of collective knowledge and can be a basis for ideological manipulation. NI researchers using this concept of narrative are often interested in social or collective forms of narrative, and in uncovering hidden narratives. This study of narrative can be reflexively applied to AI research itself, leading to transformations of AI practices. That is, an analysis of the narrative structures and metaphors used to tell the story of progress within AI can illuminate systematic problems caused by these narratives and point the way to new research approaches (Agre 1997, Sack 1992, Sengers 1998).

\section{Literary studies}

Literary studies are particularly concerned with analyzing the properties of stories as narrative. These properties can then be used as a basis for story-generation or understanding systems. For example, Vladimir Propp's analysis of the structure of folk tales (Propp 1969) has served as an inspiration for many AI researchers (e.g. Meehan 1977, Turner 1992, Weyhrauch 1997).

More generally, literary studies and literary theory embrace an enormous spectrum of perspectives on story, narrative, and their function in our culture, from Aristotle's theory of poetics to New Criticism to speech act theory to structuralism to Reader Response theory to postmodernism and beyond. Each of these strands involves novel ways of thinking about narrative and its place in human experience that can be tapped for work in NI --- the surface has barely been scratched.

\section{Drama}

Drama is the performance of stories in front of an audience in real-time (i.e. plays and movies). Dramatic stories have different properties from literary stories (i.e. novels). Following Laurel (Laurel 1991), dramatic stories have the properties of enactment, intensification, and unity of structure, vs. literary stories which have the properties of description, extensification, and episodic structure. Given the affinity between drama's focus on action and the action-based, real-time, responsive behavior of interactive computer systems, researchers have begun tapping the dramatic tradition, particularly within the areas of interface design and interactive drama. (Laurel 1991, Bates 1992, Hayes-Roth, van Gent, and Huber, 1997).

\section{NI is Humanistic AI}

As you might imagine, this highly divergent list of influences (as well as multiple understandings and definitions of the concept of narrative) has led to a healthy foment in the field. While it is not unusual for AI researchers to draw from a wide variety of other fields for inspiration, it is unusual for those fields to be largely humanistic. We believe this is a special source of interest for NI: it is a field where not only scientific but also humanist notions of experience and humanity fruitfully inform technological conceptions.

\section{The Lay of the Land}

Drawing on a diverse range of influences, researchers have (often independently) explored a wide variety of topics relevant to NI. In the process, several common themes have emerged.

\section{Narrative Interfaces}

Several researchers in the field of HCI argue that narrative should be used as a basis for human-computer interfaces (Don 1990, Laurel 1991). If humans often make sense of the world by assimilating it to narrative, then it makes sense to design our systems so as to allow people to use their well-honed narrative skills in interpreting these systems. For example, Don (Don 1990) borrows concepts from the oral storytelling tradition to organize the interface for a multimedia knowledgebase. Specifically, she describes three properties of oral storytelling that can guide interface design: storytellers adapt the story to the reactions of the audience, information such as names and lists are embedded within the storyline such that the audience experiences this information as events unfolding in time, and characters with predictable traits are used to prime expectations. Laurel (Laurel 1991) uses the analytic categories of Aristotelian dramatic theory (spectacle, song, diction, thought, character and plot) to organize interface design. 


\section{Narrative Agent Design}

The HCI argument that systems will be more understandable with narrative presentation extends to systems involving artificial agents. Since, as narrative psychologists argue, humans use narrative in particular for understanding intentional behavior, several researchers argue that agents will be more comprehensible if their visible behavior is structured into narrative (Sengers 1999, Lester and Stone 1997). This generally involves the construction of agent architectures that allow agents to make behavioral choices based on the narrative structure of the resulting behavior, often including transition behaviors that knit the agent's various activities into a coherent, narrative whole.

\section{Agents that Use Narrative Structure}

If narrative is one central component of human intelligence, then it should also play an important role in artificial agents which model aspects of human intelligence (Schank 1990, Dautenhahn and Nehaniv 1998). Roger Schank, for example, has developed a model of the interrelationship between stories and memory, describing how stories are understood and how they are recreated from the remembered "gists" of stories. Kerstin Dautenhahn argues that human (and possibly animal) experience in the world is shaped by our autobiographies, narratives we tell ourselves about our past and the pasts of other agents (Dautenhahn 1998). Chrystopher Nehaniv is building algebraic models of these autobiographies (Nehaniv and Dautenhahn 1998).

\section{Support for Human Storytelling}

Since stories are an important part of human life, several researchers, most notably in Justine Cassell's Gesture and Narrative Language Group at the MIT Media Lab, have begun building systems that support people in telling stories to one another. Some of these systems, such as Kimiko Ryokai's Storymat (Ryokai and Cassell 1999), record and play back stories that people have told. Others, like Marina Umaschi Bers's SAGE Storytellers, allow people to create their own interactive storytellers (Umaschi 1997).

\section{Story Database Systems}

Some researchers have found it useful to design systems which allow humans to access databases of stories. Presenting information in the form of narratives, they argue, makes it easier and more pleasant for people to process the information. Schank (Schank 1997) has built a training system on this principle. It contains a database of stories describing how people have handled commonly occurring problem situations; these stories are triggered by the system when the trainee faces a similar situation. Another example of this kind of work is IBM Research's project on Knowledge Socialization, which looks at among other things - ways in which story databases can be used to transfer informal knowledge (see Deborah Lawrence and John Thomas's paper in this symposium).

\section{Story-understanding Systems}

Story understanding systems seek to model the processes by which a human "understands" a story. "Understanding" is usually operationalized as the ability to answer questions about a story where the answers are not explicitly given within the story, or as the ability to paraphrase or summarize a story. In order to perform these tasks, story understanding systems from representations of stories more amenable to manipulation than the surface form, make connections between the stories and some context or background knowledge, and possibly have models of story event importance. Research in story understanding began during AI's classical engagement with narrative (see the section "A Brief History of Narrative Intelligence" above). Even after the shift in AI research agendas following the AI Winter, a small stream of such work continued (e.g. Cox 1996). This body of work plays an important role within NI. By exploring what it means to be the kind of system (either natural or artificial) that understands stories, this work can help inform the design of agents and interfaces that make use of narrative.

\section{Storytelling Systems}

Storytelling systems seek to model the knowledge and processes necessary to tell a story. Following Bailey (see his paper in this volume), work in storytelling systems can be divided into three major groups: author-centric, storycentric, and character-centric systems (Bailey refers to character-centric systems as world models). Author-centric systems model the thought processes of an author. Character-centric systems model the goals and plans of characters; stories result from characters pursuing their autonomous goals. Story-centric systems model the structural properties of stories themselves (viewing the story as an artifact); the system tells stories by manipulating this structural artifact.

Like story understanding, storytelling work also began during AI's classical engagement with narrative. Interestingly, the three perspectives outlined above all emerged during this classical engagement at roughly the same time. Perhaps the most famous early storytelling system is Tail-spin (Meehan 1977). Tailspin is a charactercentric system, modeling the goals and plans of animal characters taken from Aesop's fables. Ani (Kahn 1979), an author-centric system, generates an animation (using a square, triangle and circle to represent characters) telling a simplified version of Snow White. The system is given a high level script describing the authorial goals for the story (what should be conveyed); given this script, it makes all the detailed animation decisions necessary to tell the story. Rumelhart (Rumelhart 1975) takes a story-centric approach, capturing the notion of story as a story grammar. For more detailed descriptions of the history of storytelling systems, see both Bailey and Lang in this volume 
(though note that what Bailey calls world modeling, Lang calls author modeling).

All three storytelling approaches tend to utilize some form of combinatorial search over a space of primitive story elements. Elliott (Elliot 1998) has explored an alternative approach. His system, while using a fixed script, tells different stories by narrating the stories with different emotional emphases. The emotional behavior of the narration agent is generated by the Affective Reasoner, a cognitive appraisal model of emotion. Elliott's work demonstrates that a storytelling system can leverage the interpretive capabilities of a human observer, in this particular case the ability to understand motivations and emotions.

\section{Interactive Fiction and Drama}

Interactive fiction and drama seeks to build systems that let the audience experience the story as an interactive participant (this includes, but is not limited to, being a firstperson protagonist). System building work in this area includes approaches which don't specifically make use of AI techniques, such as hypertext fiction and text and graphical adventure games. These approaches have been quite fruitful for exploring the nature of interactivity and the structural possibilities of interactive narrative (Murray 1998). But for the purposes of this brief overview, we will focus on AI-based approaches to interactive fiction and drama.

Most of the work in interactive drama has approached it from an autonomous agents perspective. The focus has been on building believable agents that can play roles in stories. The $\mathrm{Oz}$ Project built an agent architecture (Loyall and Bates 1991, Loyall 1997) including a model of emotion (Reilly and Bates 1992, Neal Reilly 1996) to support the construction of autonomous characters. HayesRoth built agents that improvise activity around a fixed script (Hayes-Roth, van Gent, and Huber 1997). Blumberg was originally motivated by the ALife goal of building computational instantiations of ethological models of action selection (Blumberg 1994), but more recently has focused on building architectures to support the construction of characters (Kline and Blumberg, 1999). Most of the believable agents architectures make use of some reactive action-selection framework, though there has been some work on using planning techniques to ease the authorial burden (Rizzo et al. 1998).

There has been less work on building systems to support interactive plot. Some work has focused on systems that provide high level plot guidance to believable agents. For example, Weyhrauch (Weyhrauch 1997) built a dramatic guidance system that issues high-level commands to $\mathrm{Oz}$ believable agents. Blumberg and Galyean (Blumberg and Galyean 1995) explored the concept of a director giving commands to autonomous characters at multiple levels of abstraction. Other work has focused on tracking the user's progress through a fixed plot, using user actions to trigger the next part of the story. For example, Galyean (Galyean 1995) built a system that uses cinematic techniques adapted to virtual reality to guide a user through a plot. Pinhanez (Pinhanez 1997) built a system that uses a temporal calculus to trigger story events given user actions.

Both agent and plot-centric approaches are represented in this symposium, in the Interactive Storytelling Design and Narrative Agents themes.

\section{Narrative for Meta-analysis}

AI researchers are people, too. As such, narrative plays an important role in AI research. Some researchers, particularly in cultural studies, study the kinds of narratives AI researchers use in talking about their own work, and how such narratives are woven into choices about what kind of research is worth pursuing (Hayles 1999, Helmreich 1998, Doyle 1997, Sack 1997). A number of AI researchers in turn believe that studying the narratives AI researchers themselves tell can lead to a better selfunderstanding for AI, and, in turn, yield better AI research (Agre 1997, Sengers 1998).

\section{State of the Art}

Because NI researchers are working in diverse fields with often little contact with one another, it is not surprising that the papers in this symposium are similarly wide-ranging: coming from backgrounds from narrative theory to discourse processing to computer game design, involving systems from natural language processors to interactive autonomous characters to story databases. Despite this diversity, several common themes emerged from the submissions. We have organized the Symposium papers according to five of these themes:

1. What is narrative? --- papers offering interesting or controversial understandings of narrative.

2. Story is... --- papers that take strong stands about what a story is, and use this as a basis from which to construct a system (usually for story-generation).

3. Supporting Human Narrative Intelligence --- papers that take seriously humans' ability to understand narrative and to support it, for example by narrativizing technology to make it understandable.

4. Interactive Storytelling Design --- papers that focus on how Interactive Fiction or Interactive Drama systems should or can be designed.

5. Narrative Agents --- papers that describe agents which use or are used in narrative. In this section, we will give an overview of the papers in the proceedings according to these themes.

\section{What is narrative?}

Several of the papers describe innovative or commonly unrealized aspects of narrative. Marc Davis and Michael Travers give a historical overview of approaches to Narrative Intelligence in their intellectual history of the NI group at the MIT Media Lab, which they founded. The 
other papers in this section each present a new way of looking at narrative.

In "Understanding Narrative is Like Observing Agents," Guido Boella, Rossana Damiano and Leonardo Lesmo turn the common argument that people understand intentional behavior by structuring it into narrative on its head. They argue instead that people understand narrative by reducing it to recognizing the plans and motivations of agents. They use this notion of narrative as a basis for discourse processing.

Both Warren Sack and Deborah Lawrence and John Thomas focus on narrative as a social phenomenon, a theme which will reappear in Kerstin Dautenhahn's paper below. In "Social Dynamics of Storytelling: Implications for Story-Base Design", Lawrence and Thomas discuss the social dynamics of storytelling, e.g. the social factors that influence who tells what to whom. These factors become of immense importance in story database design, since they influence which stories will be told to story collectors and how they could or should be used in the story database. In "Stories and Social Networks," Sack looks at the interrelationship between stories and social relationships on the internet: which stories get re-told, who cites whom and in what way. He aims for a middle ground between computational linguistics, which he argues generally looks only at the utterances of individuals without concern for their social context, and sociology, in which social networks of storytelling are studied while often ignoring the form and content of the stories involved.

In "Narrative Theories as Contextual Constraints for Agent Interaction", John F. Meech synthesizes interface design, autonomous agents, narrative theory, and many current theories of narrative intelligence. He accomplishes this impressive feat by looking at narrative as a form of contextualization, a framework in which a number of technical fields and philosophical approaches can be seen to be working in a similar direction.

David Herman's paper, "Spatial Cognition in Naturallanguage Narratives," has perhaps the most thoroughly grounded usage of narrative in the Symposium. Herman's background is in narrative theory; in this paper, he looks at the use of space in human narratives. This detailed look at human Narrative Intelligence provides an important anchor in narrative theory for the Symposium.

\section{Story is...}

Many of the papers on story-generation are based on a clear-cut definition of story, for example "story is when someone has something, loses it, and gains it back." What is interesting is that each such story system seems to have a different definition.

In "Interactive drama on computer: Beyond linear narrative," Nicolas Szilas uses a model of story based on the notion of conflict. Such conflict occurs when a character wishes to reach a particular goal, but that goal is in conflict with the character's values. Michael Schroeder argues in "How To Tell A Logical Story" that story can be seen as a sequence of logical argumentation, which often involves an attempt to resolve a conflict. His system, Ultima Ratio, formalizes the plot of stories as logical sequences. In contrast to these content-based approaches, Paul Bailey argues in "Searching for Storiness: StoryGeneration from a Reader's Perspective", that story is fundamentally the effect it has on the reader. Bailey keeps track of the reader's presumed psychological processes in reaction to the story as a guide in continuing the generation of a story.

Two of the papers are based on ways of understanding story in terms of familiar AI techniques. In "Notes on the Use of Plan Structures in the Creation of Interactive Plot," R. Michael Young understands interactive plot generation as a form of AI planning. Plots are constructed as plans that may be effected by (and have to be reconstructed after) user's autonomous actions. In "A Declarative Model for Simple Narrative", R. Raymond Lang argues for the generation of stories using a formalized story grammar.

Finally, Selmer Bringsjord and Dave Ferrucci argue against all these definitions of story in "BRUTUS and the Narrational Case Against Church's Thesis." They state that the proper definition of story is that there is no simple definition. They believe that story is fundamentally undecidable.

\section{Supporting Human Narrative Intelligence}

Several papers deal with human narrative intelligence, i.e. the human ability and perhaps even compulsion to make sense of the world through narrative and storytelling. In "The Lemur's Tale - Story-Telling in Primates and Other Socially Intelligent Agents," Kerstin Dautenhahn discusses the social and evolutionary roots of human narrative intelligence. She argues from an anthropological and sociological perspective that storytelling has evolved in response to the social structure and social dynamics of primate communities.

Other researchers in this area have built systems that support this human narrative intelligence. Marina Umaschi Bers's "Narrative Construction Kits: 'Who am I? Who are you? What are we?'" describes several interactive storytelling systems that are intended to help children think about their own identity. Bers argues that identity can be meaningfully thought of in terms of a "society of self," analogous to Marvin Minsky's "society of mind," in which different aspects of personality can be combined. She argues that narrative plays an essential role in creating a cohesive sense of self out of these diverse and potentially conflicting "subselves."

Justine Cassell and Jennifer Smith's "The Victorian Laptop: Narrative Engagement through Place and Time," like Bers's paper a product of Cassell's Gesture and Narrative Language group, also describes an interactive storytelling system. In the Victorian Laptop are stored travel narratives; people can enter their own travelogues, and the system will search through a database of stories to find historical travelogues that are similar to it. Interestingly, it did not really matter how good the storymatching algorithm was, because people could always find 
ways in which stories connect to each other: human narrative intelligence at work.

In "AGNETA \& FRIDA: A Narrative Experience of the Web?," Per Persson describes techniques for narrativizing user experience of the Web, normally a disjointed series of jumps from page to page. While accompanying the user along their Web surf, the characters Agneta and Frida engage in a narrative banter: making (usually sarcastic) comments about what they see on the Webpage, commenting on error messages, but also discussing (and living!) their own lives in soap-opera-like vignettes: complaining about the annoying poodle that lives next door or going to the kitchen (off-screen) to make a cup of coffee. The hope is that playing a narrative alongside and connected to the Web browsing experience will help to provide an overall sense of cohesion to the user's experience of web surfing.

Finally, in "Towards Narrative-Centered Learning Environments," Bradford W. Mott, Charles B. Callaway, Luke S. Zettlemoyer, Seung Y. Lee, and James C. Lester describe the potential for virtual environments which use narrative as a supporting element for education. Rich stories with compelling characters may provide an environment which better motivates students to become involved in the environment and to care about the material being presented. At the same time, working within an interactive narrative --- in which a child can help to create the narrative, explore the narrative actively, or reflect upon its narrative content afterwards --- provides new opportunities for effective learning situations.

\section{Interactive Storytelling Design}

The papers describing interactive storytelling systems all emphasize the importance of the audience experience - the focus of system building is not to build models of a story author's or story understander's internal process, to seek the fundamental nature of story, or to understand or leverage the use of narratives in cognition, but rather to provide audiences with an interesting and pleasurable interactive story experience.

In "Assumptions underlying the Erasmatron interactive storytelling engine," Chris Crawford describes the design assumptions underlying his interactive storytelling tool Erasmatron. Crawford argues that interactive storytelling tools should steer clear from general, algorithmic descriptions of storyness (nicely compatible with Bringsjord's and Ferrucci's position) and focus on providing artists control over the story. To provide the artist control while providing the audience with a truly interactive experience, Crawford argues that neither plotcentric nor character-centric approaches to story are useful; the Erasmatron is based on an alternative verb-centric approach to interactive story.

In "Once upon a Time," Isabel Machado, Carlos Martinho and Ana Paiva describe a storytelling environment designed to support improvisational dramatic games for young children. In order to understand the requirements for such a system, the authors performed an observational study of children creating dramatic stories. This study provided an understanding of how children choose a story theme and character, act within the role of their character, and how a teacher can provide scaffolding during the improvisational experience. The authors discuss the design concerns arising out of this understanding.

In "The Dr. K--- Project," Brandon Rickman describes a text-based interactive narrative system. As the audience selects words in the textual narrative, the object or action is brought into focus, causing the system to redescribe the object or action in more detail. Simultaneously, other descriptions may become less detailed, reverting to more generic descriptions. The scene is in continuous flux - the narrative is not unfolded in a linear manner but rather is communicated as a gestalt created by the entire interaction. Rickman contrasts the notion of simulation and fabrication. Where simulations try to provide objective, repeatable, high-fidelity experiences with an emphasis on user control, fabrications provide more indirect user control, a small number of specific viewpoints on the world, and try to expose the representational process. "Dr. K---" can be understood as a fabrication.

In "The Rise and Fall of Black Velvet Flag: An 'Intelligent' System for Youth Culture Documentary" Sheldon Schiffer describes an interactive documentary system that documents the band Black Velvet Flag. A user traverses a custom path through the documentary materials by using a visual query interface. Schiffer is particularly interested in using interactivity to maintain the dynamism of the original source materials. He argues that maintaining this dynamism is particularly appropriate for documenting youth cultural phenomena.

In "The Chorus as Internalized Objects," Carol Strohecker presents a design sketch for a system that would enable multiple users to interact in a manner reminiscent of a Greek Chorus. She draws on the psychoanalytic literature regarding introjection, the process of constructing emotionally charged inner objects. Internalized objects serve as a design inspiration for computational objects that would support and organize multiple users in their role as collective commentators on a story.

\section{Narrative and Agents}

With the recent surge of interest in autonomous agents has come a lot of interest in the intersection between agents and narrative: agents as characters in stories, agents that can tell stories, agents that use narrative to understand themselves in ways in which many believe humans do. Ruth Aylett and Andrew Stern look at the possibilities for using autonomous agents as characters within interactive fiction. In "Narrative in Virtual Environments - Towards Emergent Narrative," Aylett describes many of the issues that arise when narrative can or should emerge from the interactions of autonomous agents within a simulated virtual environment. Stern argues in "Virtual Babyz: Believable Agents with Narrative Intelligence" that narratives ("mini-stories") can in fact emerge from the 
interactions between characters who are modeled as autonomous agents. He describes the engineering techniques that were used in order to support the development of narrative in the product Virtual Babyz.

Timothy Bickmore and Justine Cassell describe the realestate-selling and small-talking agent Rea in "Small Talk and Conversational Storytelling In Embodied Conversational Interface Agents." Rea uses the ability to tell stories as a way of building trust with her clients, who may otherwise be put off by the fact that she is only a program. More storytelling agents are described by Katherine Isbister and Patrick Doyle in their paper, "Touring Machines: Guide Agents for Sharing Stories about Digital Places." The guide agents tell stories on virtual tours, tailoring the story content and complexity to the audience.

Chrystopher Nehaniv focuses on narrative as memory for biological and artificial agents in "Narrative for Artifacts: Transcending Context and Self." Narrative provides a means for agents to escape from pure reactivity to sensory data. Used as both an internal and external means of communication, narratives allow agents to broaden their temporal horizon.

\section{Narrative is Many, not One}

NI is radically interdisciplinary, drawing on narrative concepts from many humanistic fields of study. Narrative is not a single entity or a single, tightly related set of concepts. As the term is used in humanistic discourse, narrative can mean many things. Narrative can mean a tightly woven story communicated by a strong authorial voice to an audience. Narrative can mean the internal imposition of coherence by which a person makes sense of her life, or the communally constructed group memory by means of which a group organizes past experience. In the broadest sense, narrative can mean an entire worldview (as in "grand" or "master" narrative). And within each of these gross distinctions, there lie yet more distinctions. For example, within the notion of narrative as a tightly woven, author-given story, there lie distinctions such as literary, cinematic and dramatic stories, each of which has its own set of properties and corresponding inspirations and design implications for NI researchers. Thus narrative is a family resemblance concept, a cover term for a rich set of ideas.

The richness of narrative presents some interesting challenges for the emerging field of NI. One challenge is to maintain open lines of communication; with so many different inflections of the concept of narrative, workers will have to make an effort to be clear on the notion of narrative they are using and how it relates (or doesn't relate) to other notions of narrative.

Another challenge will be to remain true to the richness of narrative. AI, like the rest of computer science, tends to prefer general and abstract formulations. Applied to narrative, this will result in the attempt to assimilate all narrative phenomena to a single, simplified formulation. In order to build systems, abstraction and simplification are necessary tools. The danger lies in forgetting for what purpose a simplification was made or perhaps that a simplification has even occurred. With a concept as complex and evocative as narrative, there will be particularly strong pressure to elide simplification. If this were to happen, the original richness of narrative, an endless source of inspiration and delight, would be lost.

\section{References}

Agre, P. Computation and Human Experience. Cambridge, UK: Cambridge University Press. 1997.

Barrett, E. The Society of Text: Hypertext, Hypermedia and the Social Construction of Knowledge. Cambridge, Massachusetts: MIT Press. 1989.

Bates, J. Virtual Reality, Art, and Entertainment. Presence: The Journal of Teleoperators and Virtual Environments 1(1): 133-138. 1992.

Blair, D. and Meyer, T. Tools for an Interactive Virtual Cinema. In Creating Personalities for Synthetic Actors: Towards Autonomous Personality Agents. Ed. Robert Trappl and Paolo Petta. Berlin: Springer Verlag, 1997.

Blumberg, B. Action-Selection in Hamsterdam: Lessons from Ethology. In From Animals To Animats Proceedings of the Third International Conference on the Simulation of Adaptive Behavior. Cambridge, MA: MIT Press, 1994.

Blumberg, B., and Galyean, T. Multi-level Direction of Autonomous Creatures for Real-Time Virtual Environments. In Proceedings of SIGGRAPH 95, 1995.

Bolter, J.D., Joyce, M. Hypertext and Creative Writing. In Hypertext '87 Proceedings. 1987.

Bruner, Jerome. Acts of Meaning. Cambridge, MA: Harvard University Press, 1990.

Bruner, Jerome. The narrative construction of reality. Critical Inquiry 18, 1, 1-21. 1991.

Carbonell, J. Subjective understanding: Computer models of belief systems. Ph.D. Thesis, Computer Science Department, Yale University. 1979.

Cox, M. Introspective Multistrategy Learning: Constructing a Learning Strategy under Reasoning Failure. Ph.D. Thesis. Technical Report GIT-CS-96/01. Computer Science Department, Georgia Institute of Technology. Atlanta, Georgia. 1996.

Cullingford, R. SAM. In Inside Computer Understanding: Five Programs Plus Miniatures, Ed. Roger Schank and Christopher Riesbeck. Hillsdale, New Jersey: Lawrence Erlbaum Associates. 1981

Dautenhahn, Kerstin. Meaning and Embodiment in LifeLike Agents. In Plenary Working Papers in Computation for Metaphors, Analogy and Agents. Ed. Chrystopher Nehaniv. University of Aizu Technical Report 98-1-005. 1998. pp. 24-33. 1998.

Dautenhahn, Kerstin and Chrystopher Nehaniv. Artificial 
Life and Natural Stories. In International Symposium on Artificial Life and Robotics (AROB III) (Beppu, Oita, Japan, 1998), vol 2, pp 435-439. 1998.

Domike, S.; Mateas, M.; and Vanouse, P. The recombinant history apparatus presents: Terminal Time. Forthcoming. 1999.

Don, Abbe. Narrative and the interface. In The Art of Human-Computer Interface Design. Ed. Brenda Laurel. Reading, MA: Addison-Wesley, pp 383-391. 1990.

Doyle, Richard. On Beyond Living: Rhetorical Transformations of the Life Sciences (Writing Science). Stanford University Press, 1997.

Dyer, M. In Depth Understanding: A Computer Model of Integrated Processing for Narrative Comprehension. Cambridge, MA: MIT Press. 1983.

Elliott, Clark, Jacek Brzezinski, Sanjay Sheth and Robert Salvatoriello. Story-morphing in the Affective Reasoning paradigm: Generating stories semi-automatically for use with emotionally intelligent' multimedia agents. In Proceedings of the Second International Conference on Autonomous Agents. Eds. Katia P. Sycara and Michael Wooldridge. New York: ACM Press, 1998.

Galyean, Tinsley. Narrative Guidance of Interactivity. MIT Media Lab Ph.D. Thesis. 1995.

Grudin, J. The computer reaches out: the historical continuity of interface design. In Proceedings of the CHI'89 Conference on Human Factors in Computer Systems. 1989.

Hayles, N. Katherine. How We Became Posthuman: Virtual Bodies in Cybernetics, Literature, and Informatics. Chicago: University of Chicago Press, 1999.

Hayes-Roth, B., van Gent, R., and Huber, D. Acting in character. In R. Trappl and P. Petta (eds.), Creating Personalities for Synthetic Actors. Berlin; New York: Springer, 1997.

Helmreich, Stefan. Silicon Second Nature: Culturing Artificial Life in a Digital World. University of California Press, 1998.

Kahn, M. Creation of computer animation from story descriptions. Ph.D. Thesis, Artificial Intelligence Lab, Massachusetts Institute of Technology. AI technical report 540. Boston, MA: 1979.

Kline, C., and Blumberg, B. The Art and Science of Synthetic Character Design. In Proceedings of the AISB 1999 Symposium on AI and Creativity in Entertainment and Visual Art, Edinburgh, Scotland. 1999.

Kolodner, J. Retrieval and organizational strategies in conceptual memory: a computer model. Hillsdale, New Jersey: Lawrence Erlbaum Associates. 1984.

Laurel, Brenda. Computers as Theatre. Reading, MA: Addison-Wesley, 1991.

Lester, James and Brian Stone. Increasing believability in animated pedagogical agents. In Proceedings of the First
International Conference on Autonomous Agents. Ed. W. Lewis Johnson. ACM Press, February 1997.

Lieberman, Henry. The Visual Language of Experts in Graphic Design. IEEE Symposium on Visual Languages, 1995.

Loewgren, J. Perspectives on Usability. Technical Report LiTH-IDA-R-95-23. Department of Computer and Information Science, Linkoping University, Linkoping Sweden. 1995.

Loyall, A.B., and Bates, J. Hap: A Reactive, Adaptive Architecture for Agents. Technical Report CMU-CS-91147, School of Computer Science, Carnegie Mellon University, Pittsburgh, PA. 1991.

Loyall, A.B. Believable Agents. Ph.D. Thesis, Department of Computer Science, Carnegie Mellon University. Technical Report CMU-CS-97-123. 1997.

Mateas, M., Domike, S., and Vanouse, P. Terminal Time: An Ideologically-Biased History Machine. In Proceedings of the 1999 AISB Symposium on Artificial Intelligence and Creative Language: Stories and Humor. Edinburgh, Scotland. 1999

Meehan, J. The metanovel: writing stories by computer. Ann Arbor: University Microfilms International, 1977.

Mueller, E. Daydreaming in humans and machines: a computer model of the stream of thought. Norwood, New Jersey: Ablex. 1990.

Murray, Janet. Hamlet on the Holodeck. Cambridge, MA: MIT Press, 1998.

Neal Reilly, W. S. Believable Social and Emotional Agents. Ph.D. Thesis, Department of Computer Science, Carnegie Mellon University. Technical Report CMU-CS96-138. 1996.

Nehaniv, Chrystopher and Kerstin Dautenhahn. Embodiment and Memories --- Algebras of Time and History for Autobiographic Agents. In Cybernetics and Systems '98 (Proceedings of the 14th European Meeting on Cybernetics and Systems Research Symposium on Embodied Cognition and Artificial Intelligence). Ed. Robert Trappl. Vol. 2, pp 651-656, 1998.

Nelson, Katherine, ed. Narratives from the crib. Cambridge, Mass. : Harvard University Press, 1989.

Pinhanez, C. Interval Scripts: a Design Paradigm for StoryBased Interactive Systems. In Proceedings of CHI 97, pp. 287-294, 1997.

Propp, Vladimir. Morphology of the Folktale. Trans. Laurence Scott. Ed. Louis A. Wagner. 2nd edition. Univ. of Texas Press: 1969.

Reilly, W.S., and Bates, J. Building Emotional Agents. Technical Report CMU-CS-92-143, School of Computer Science, Carnegie Mellon University, Pittsburgh, PA. 1992.

Rizzo, P., Veloso M.V., Miceli M., Cesta A. Goal-Based Personalities and Social Behaviors in Believable Agents. 
Applied Artificial Intelligence, 13:239-271, 1998.

Rumelhart, D. E. Notes on a schema for stories. In Representation and Understanding: Studies in Cognitive Science, Bobrow, D. G., and Collins A., eds, pp 211-236. New York: Academic Press, Inc., 1975.

Ryokai, Kimiko and Justine Cassell. StoryMat: A Play Space with Narrative Memories. In Proceedings of the 1999 International Conference on Intelligent User Interfaces. Posters/Demonstrations. p. 201. 1999.

Sack, W. Knowledge Compilation and the Language Design Game. In Intelligent Tutoring Systems, Second International Conference (Lecture Notes in Computer Science), Claude Frasson, Gilles Gauthier, and Gordan McCalla (editors). Berlin: Springer-Verlag. 1992.

Sack, W. Artificial Human Nature. Design Issues, Volume 13 (Summer 1997): pp 55-64. 1997.

Schank, R. and Reisbeck, C. (eds). Inside Computer Understanding: Five Programs Plus Miniatures, Hillsdale, New Jersey: Lawrence Erlbaum Associates. 1981.

Schank, R. Tell me a story: A new look at real and artificial memory. New York: Scribner, 1990.

Schank, R. Virtual Learning: A Revolutionary Approach to Building a Highly Skilled Workforce. McGraw-Hill. 1997.

Sengers, P. Anti-Boxology: Agent Design in Cultural Context. Ph.D. Thesis, School of Computer Science, Carnegie Mellon University. Technical Report CMU-CS98-151. 1998.

Sengers, Phoebe. Designing Comprehensible Agents. Sixteenth International Joint Conference on Artificial Intelligence. Vol 2., pp. 1227-1232. 1999.

Turner, S. MINSTREL: a computer model of creativity and storytelling. Ph.D. Thesis, Computer Science Department, University of California, Los Angeles. Technical Report CSD-920057. 1992.

Umaschi, Marina. Soft Toys with Computer Hearts: Building Personal Storytelling Environments. In $\mathrm{CHI}^{\prime} 97$ Proceedings. ACM, pp. 20-21. 1997.

Weyhrauch, Peter. Guiding Interactive Drama. Ph.D. Thesis, School of Computer Science, Carnegie Mellon University. Technical Report CMU-CS-97-109. Pittsburgh, PA: 1997.

Wilensky, R. PAM. In Inside Computer Understanding: Five Programs Plus Miniatures, Ed. Roger Schank and Christopher Riesbeck. Hillsdale, New Jersey: Lawrence Erlbaum Associates. 1981.

Winograd, T. (Ed). Bringing Design to Software. New York, N.Y.: ACM Press. 1996. 